\title{
Comparison of Current Control Techniques for Active Filter Applications
}

\author{
Simone Buso, Member, IEEE, Luigi Malesani, Fellow, IEEE, and Paolo Mattavelli, Associate Member, IEEE
}

\begin{abstract}
This paper presents the comparative evaluation of the performance of three state-of-the-art current control techniques for active filters. The linear rotating frame current controller, the fixed-frequency hysteresis controller, and the digital deadbeat controller are considered. The main control innovations, determined by industrial applications, are presented, suitable criteria for the comparison are identified, and the differences in the performance of the three controllers in a typical parallel active filter setup are investigated by simulations.
\end{abstract}

Index Terms - Active filters, current control, voltage-source inverters.

\section{INTRODUCTION}

A S FAR AS THE quality of current control is concerned, parallel active filters represent an extremely demanding field of application for voltage-source pulsewidth modulation (PWM) converters. In fact, differently from what happens in the adjustable-speed drive or in the PWM rectifier applications, the current control of these devices is required to generate a current waveform which is normally characterized by a considerable harmonic content. As an example, a typical application of parallel active filters is represented by the compensation of controlled or naturally commutated rectifiers, especially for the so-called retrofit of existing plants. To compensate for the distorted current drawn by the rectifiers from the utility grid, the active filter and its current control must have the capability to track sudden slope variations in the current reference, corresponding to very high $d i / d t$ values, which makes the design of the control and the practical implementation of the filter particularly critical. To meet these dynamic requirements, a current-controlled voltage-source inverter (VSI) is a suitable solution. As far as the control is concerned, the variability of the frequency and amplitude of the voltage faced by the VSI in an ac drive or the current reference variations due to power absorption changes in a PWM rectifier, which may represent significant problems for those applications, are undoubtedly less critical requirements than those demanded by the filter applications. Therefore, it is in the active power filter application that the choice and implementation of the current regulator is more important for the achievement of a satisfactory performance level.

Manuscript received April 29, 1997; revised June 1, 1998. Abstract published on the Internet July 3, 1998.

S. Buso is with the Department of Electronics and Informatics, University of Padova, 35131 Padova, Italy.

L. Malesani and P. Mattavelli are with the Department of Electrical Engineering, University of Padova, 35131 Padova, Italy.

Publisher Item Identifier S 0278-0046(98)07019-1.
The current control techniques [1]-[4] that have so far demonstrated the most effective performance in practical applications to the control of active power filters are the linear current control, the digital deadbeat control, and the hysteresis control. In principle, analog control techniques have the fastest speed of response, not being delayed by any $\mathrm{A} / \mathrm{D}$ conversion process or calculation time. Among the digital solutions, the deadbeat control algorithm is known to ensure the best dynamic response. For these reasons and according to the practical experience, the two aforementioned analog techniques, that is, the linear current control and the hysteresis control, together with the digital deadbeat control, have been considered in this paper. Each of these have undergone a substantial evolutionary process, due their diffused industrial applications, so that the actually employed techniques indeed feature a large number of refinements with respect to the originally introduced versions. This paper is aimed at both summarizing the main implementation refinements which characterize the latest versions of the aforementioned control techniques and comparing the different performance [5], [6] achieved by the three current controls in a typical active filter applicative situation, considering the state-of-the art implementation of each one, so as to achieve simulated results which are as realistic as possible.

The organization of this paper is as follows. This paper initially focuses on the identification of proper criteria for correctly comparing the three controllers' performance. Then, after a short description of the principles of the three control techniques and the presentation of the main refinements, the simulated system is briefly described. Finally, the results of the comparison, which is done according to the chosen criteria, are discussed.

\section{CRiteria FOR CURREnT CONTROllers' COMPARISON}

A key point in the comparative evaluation of different control strategies, together with the selection of a realistic test situation, is the definition of suitable criteria [6] to evaluate the performance level offered by each of the considered techniques.

In the case this paper deals with, that is, an active filter application, an immediate criterion for the control's quality evaluation seems to be the measurement of the total harmonic distortion (THD) of the line current waveform. This gives direct information about the control's capability of eliminating harmonic pollution from the current drawn from the utility grid. As a matter of fact, the insight given 
by this measurement is rather poor, since all the various aspects of current regulation's quality are lumped in a single figure. Therefore, two additional criteria are taken into account here.

One is the calculation of the rms value of the current error which, of course, is related to the energy of the error and, therefore, to the dynamic performance of the current controller. Differently from the current THD, this index includes the fundamental harmonic, namely, the error in the compensation of its reactive component.

The last criterion considered here is the evaluation of the line current spectrum, which, above all, identifies the distribution of current harmonics in the different frequency ranges. This is a very important point, both for the design of the passive filters smoothing the modulation ripple at the input of the compensation system and for the evaluation of the capability of the different control techniques to meet the International Electrotechnical Commission (IEC) standards' requirements.

\section{Current Control Techniques}

This section presents the considered control techniques, providing for each of them both a short description of the basic features and the discussion of the main refinements characterizing the state-of-the-art implementations. In the following, it will be assumed that the converter, used as the active filter, operates as a controlled current source. The generated phase current, therefore, tracks a reference obtained by subtracting the load current to the desired, compensated line current. This latter, in turn, is usually taken by the supply voltage waveform, with an amplitude which ensures the power balance of the system [7], [8].

\section{A. Linear Current Control}

The conventional version of the linear current controller performs a sine-triangle PWM voltage modulation of the power converter using as the modulating signal the current error filtered by a proportional integral (PI) regulator. It is worth noting that we have here considered the original analog implementation of the PWM technique, since it ensures to the system the fastest possible speed of response. A sudden change in the modulating signal is indeed instantaneously turned into a duty-cycle variation, without the unavoidable delay equal to one-half of the modulation period, in the case of space-vector modulation (SVM), or to a whole modulation period, in the case of sampled PWM. The application of these modulation techniques can only reduce the system's speed of response. Nevertheless, the linear current control technique with analog PWM, although very simply implementable by means of analog circuitry, provides a rather unsatisfactory performance level as far as active filter applications are concerned. This is mainly due to the limitation of the achievable regulator bandwidth which, as it is well known, is implied by the necessity of sufficiently filtering the ripple in the modulating signal. This necessity compels one to keep the loop gain crossover frequency well below the modulation frequency. This re-

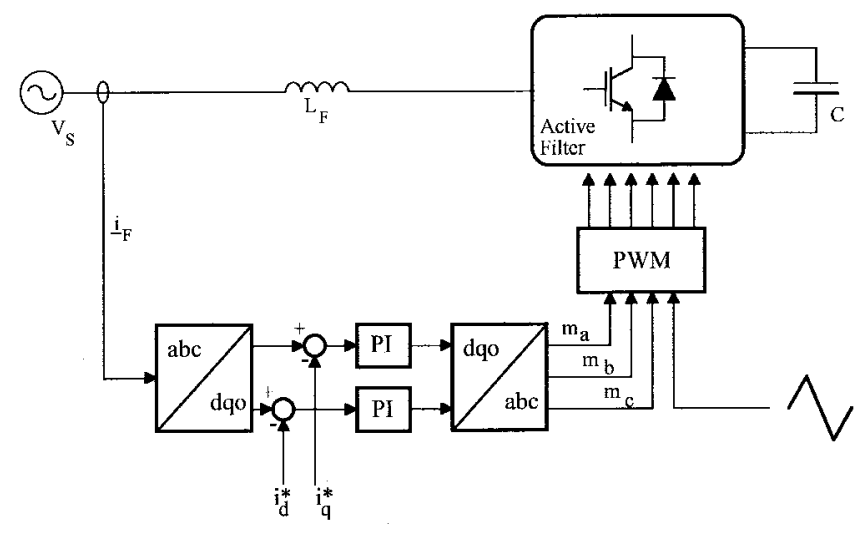

Fig. 1. Basic scheme of a linear rotating frame current regulator; $i_{F}$ is the active filter current vector ( $a b c$ frame).

flects in a poor rejection of the disturbances injected into the current control loop, mainly due to the ac line voltage at the fundamental frequency. To overcome this limitation, recent versions of the linear current control exploit the $d-q$ rotating frame [9]-[12]. Control variables are mapped into the rotating frame according to the scheme represented in Fig. 1. It is noticeable that, for this kind of application, to perform the $d-q$ transformation, there is no need to know the instantaneous phase angle of the sinusoidal waveforms. The main advantage of such a solution is that the fundamental harmonic components of voltage and current signals appear constant to the current regulator. Therefore, the line voltage, which is almost sinusoidal, is seen by the current regulator as a constant quantity. As a consequence, the rejection of this disturbance is much more effective. On the other hand, the bandwidth limitation of the PI regulators, which remains unchanged, still implies significant errors in the tracking of the high-order harmonic components of the current reference. In active filter applications, these errors usually reflect in a not completely satisfactory quality of harmonic compensation.

\section{B. Digital Deadbeat Control}

As described in [13], an effective exploitation of the advantages of the digital current control can be achieved by adopting an improved version of the well-known deadbeat control technique [14]-[18]. In the conventional implementation, the digital control calculates the phase voltage, so as to make the phase current reach its reference by the end of the following modulation period [19]-[22]. The calculations are often performed in the $\alpha, \beta$ frame, and the space-vector modulation (SVM) strategy, which very well suits the digital implementation, is applied to the switching converter. This is essentially the situation depicted in Fig. 2. An important advantage of this technique is that it may not require the line voltage measurement in order to generate the current reference. Indeed, the deadbeat control's algorithm implies an estimation of the line voltage instantaneous value, which can, therefore, also be used for the current reference generation. On the other hand, the inherent delay due to the calculations is indeed a serious drawback for this technique [13], [22]. 


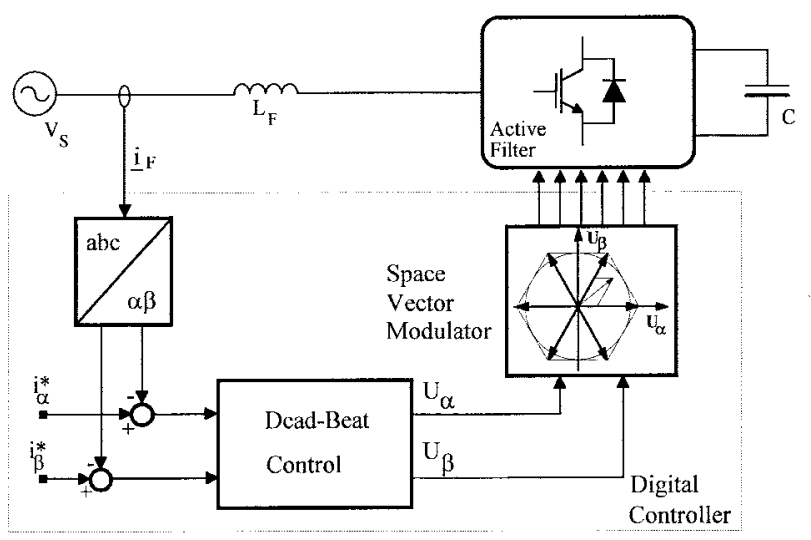

Fig. 2. Basic scheme of a digital deadbeat current regulator; $i_{F}$ is the active filter current vector.

Due to the high required speed of response, it becomes the main limitation in active filter applications and may imply an unsatisfactory performance level. In the more recent versions [13] of the deadbeat controller, this delay is reduced by sampling the control variables and executing the control routines twice in a modulation period. The turn-on and turnoff times of the power converter switches are, therefore, decided separately in two successive control periods. As a consequence, the aforementioned delay in current reference tracking can be reduced to a single modulation period. This can be further compensated by adopting a prediction technique for the current reference [13]. Accordingly, the control algorithm interpolates the reference value for the current modulation period from those calculated in the preceding ones. Thus, by anticipating the current reference, the steadystate tracking error can be virtually eliminated. On the other hand, the implied derivative action causes increased errors and overshoots in the presence of sudden reference changes. In practice, however, it turns out that, on the whole, the reference prediction technique provides a performance improvement. Another key issue in this kind of control technique is the effect of the input filters commonly used to eliminate residual high-frequency harmonic components in the line currents, which are due to the inverter's modulation. These filters are not normally accounted for in the control algorithm and may, therefore, undermine the stability of the current loop. To guarantee the control's stability, a certain oversizing of the system's reactive components may be necessary [23].

\section{Hysteresis Control}

The basic implementation of the hysteresis current controller derives the switching signals from the comparison of the current error with a fixed hysteresis band. Although simple and extremely robust, this control technique exhibits several unsatisfactory features [24]. The main one is that it produces a varying modulation frequency for the power converter. This is, in general, responsible for various problems, from the difficulty in designing the input filters to the generation of unwanted resonances on the utility grid. Another negative aspect of the basic hysteresis control is that its performance is negatively affected by the phase currents' interaction, which is typical of three-phase systems with insulated neutral. Many improvements to the original control structure have been suggested by industrial applications [25]-[27]. First of all, phase current decoupling techniques have been devised [27]. Secondly, fixed modulation frequency has been achieved by a variable width of the hysteresis band as function of the instantaneous output voltage [27], [28]. This is achieved either by means of a phase-locked loop (PLL) control or by a feedforward action operating on the control thresholds [29]-[31]. Fig. 3 shows the simplified scheme of the implementation of such a controller. As can be seen, the controller modifies the hysteresis band by summing two different signals. The first is the filtered output of a PLL phase comparator $\left(\beta_{1}\right)$, and the second is the filtered output of a band estimation circuit $\left(\beta_{2}\right)$. The band estimator implements a feedforward action that helps the PLL-based circuit to keep the switching frequency constant; in this way, the output of the PLL circuit only provides the small amount of the modulation of the hysteresis band which is needed to guarantee the phase lock of the switching pulses with respect to an external clock signal. This also ensures the control of the mutual phase of the modulation pulses. All of these provisions have allowed a substantial improvement in the performance of the hysteresis current controller, as is discussed in [31]. It is worth adding that, in different applications, such as drives or PWM rectifiers, such control complexity may not be actually necessary, since the required dynamic performance is normally lower, and conventional, nonhysteretic, techniques can be completely satisfactory.

\section{ThE Simulated SysteM}

The ratings of the simulated system used for the evaluation of the current controllers' performance are reported in Table I. These are typical for the considered application power rating. Fig. 4 shows the scheme of the considered plant. As can be seen, a controlled thyristor rectifier with inductive load has to be compensated by the parallel active filter [32]. In the medium-power range, as that of the load considered here, the compensation of the load reactive power is more and more often performed by the active filter itself, with no need for passive compensation filters. This is mainly justified by the decreasing cost of semiconductors (and of electrolytic capacitors). Moreover, this solution allows one to efficiently cope with sudden variations of the load reactive power, which is typical in thyristor rectifiers. The active filter is implemented by means of a three-phase VSI. The current control of the filter operates the switches so as to generate a suitable current $i_{F}$. The current reference $i_{F}^{*}$ is derived by subtracting the load current $i_{L_{R}}$ from the line current reference $i_{S}^{*}$, which represents the current desired after the compensation to achieve the required unity power factor. The signal $i_{S}^{*}$ is obtained by multiplying the input voltage waveform $V_{S}$ and a proper scaling factor. The voltage scaling factor is determined by the outer control loop (PI), 


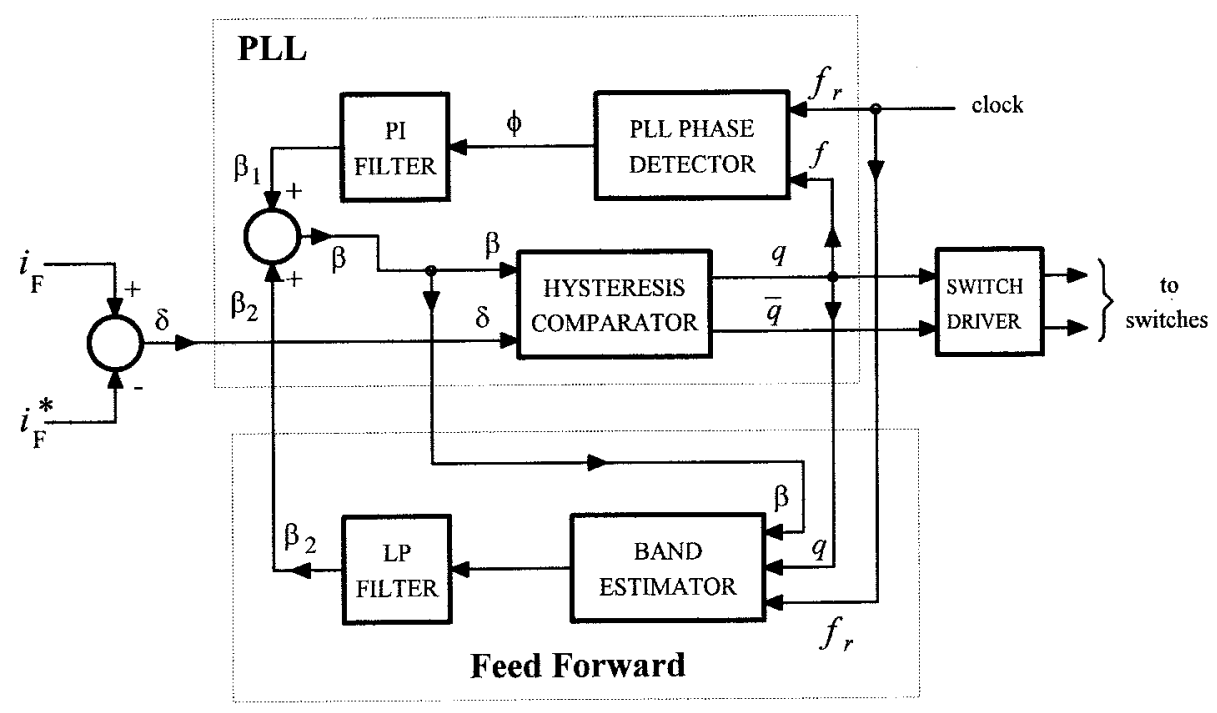

Fig. 3. Basic scheme of a hysteresis current regulator.

TABLE I PRototype RATINGS

\begin{tabular}{ll}
\hline Input Voltage & $\mathrm{V}_{\mathrm{S}}=380 \mathrm{~V}_{\mathrm{RMS}}$ \\
Rectifier Load Rated Power & $\mathrm{P}_{\mathrm{n}}=100 \mathrm{~kW}$ \\
Rectifier Input Inductor & $\mathrm{L}_{\mathrm{R}}=100 \mu \mathrm{H}$ \\
Rectifier Load Inductor & $\mathrm{L}=750 \mu \mathrm{H}$ \\
Rectifier Load Current & $\mathrm{I}_{\mathrm{L}}=150 \mathrm{~A}$ \\
Switching Frequency & $\mathrm{f}_{\mathrm{SW}}=10 \mathrm{kHz}$ \\
Active Filter Inductor & $\mathrm{L}_{\mathrm{F}}=250 \mu \mathrm{H}$ \\
Active Filter DC Link Capacitor & $\mathrm{C}=2500 \mu \mathrm{F}$ \\
Active Filter DC Link Voltage & $\mathrm{E}=750 \mathrm{~V}$ \\
\hline
\end{tabular}

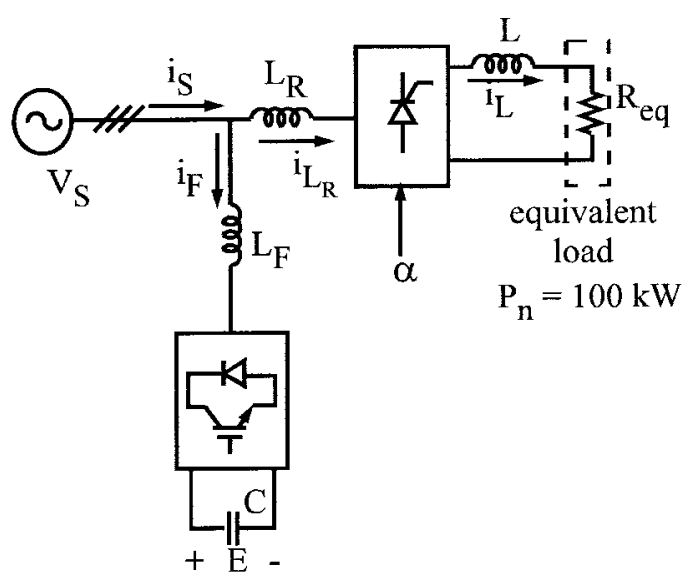

Fig. 4. Scheme of the simulated system.

so as to balance the active filter losses and, therefore, to keep the dc-link voltage $E$ on the filter capacitor $C$ constant. The scheme of the complete control structure is shown in Fig. 5.

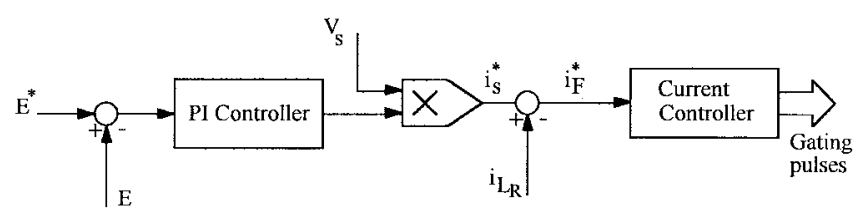

Fig. 5. Scheme of the control system.

In order to limit the maximum slope of the load current $i_{L_{R}}$ within the compensation capability of the active filter, a smoothing inductor $L_{R}$ has been inserted before the rectifier. With a proper sizing of $L_{R}$, which takes into account the filter parameters $\left(f_{s w}, L_{F}, E\right)$, the inverter saturation is prevented, even in correspondence of rectifier commutations.

Since the compensation error strongly depends on the rectifier current derivative at thyristors turn-on, two different firing angles are taken into account $\left(\alpha=0^{\circ}\right.$ and $\left.\alpha=40^{\circ}\right)$, corresponding to a quite slow and to a steep current variation, respectively. To maintain similar operating conditions, the rectifier load resistance $R_{\mathrm{eq}}$ is reduced at $\alpha=40^{\circ}$ with respect to $\alpha=0^{\circ}$, so that the rectifier's dc current is the same in both cases.

\section{Simulation Results}

The system of Fig. 4 has been simulated using each one of the previously described current control techniques for the active filter. The controllers include the implementation of all the aforementioned refinements, so that the achieved performance is, as realistically as possible, at its best level [5].

Figs. 6 and 7 describe the system's operation with the digital deadbeat control for $\alpha=0^{\circ}$ and $\alpha=40^{\circ}$, respectively. In particular, the upper part of Fig. 5 shows the relevant system's waveforms; these are the line voltage $V_{S}$, the line current $i_{S}$, the rectifier current $i_{L_{R}}$, the active filter current $i_{F}$ superimposed to its reference $i_{F}^{*}$, and the current error $\epsilon_{S}$. On the bottom, the corresponding line current spectrum, referred to the amplitude of the fundamental current, is shown. The 
(a)

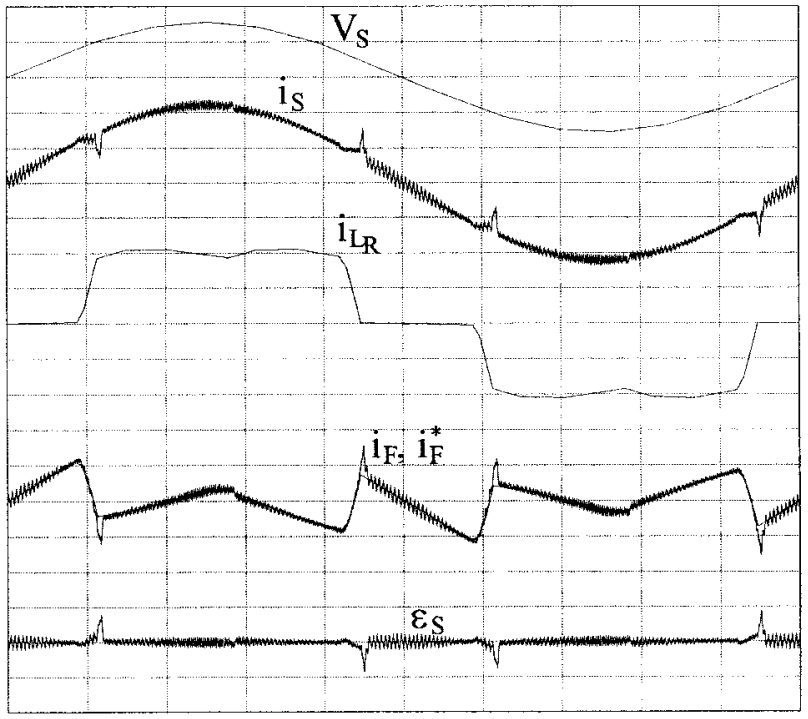

(b)

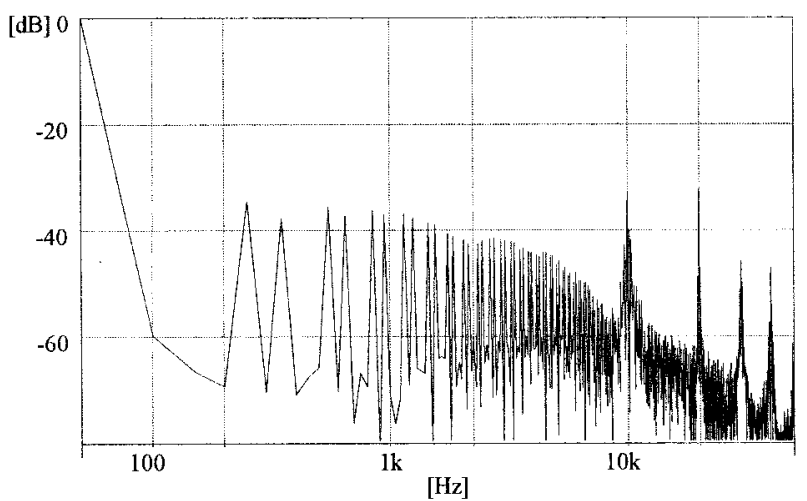

(a)
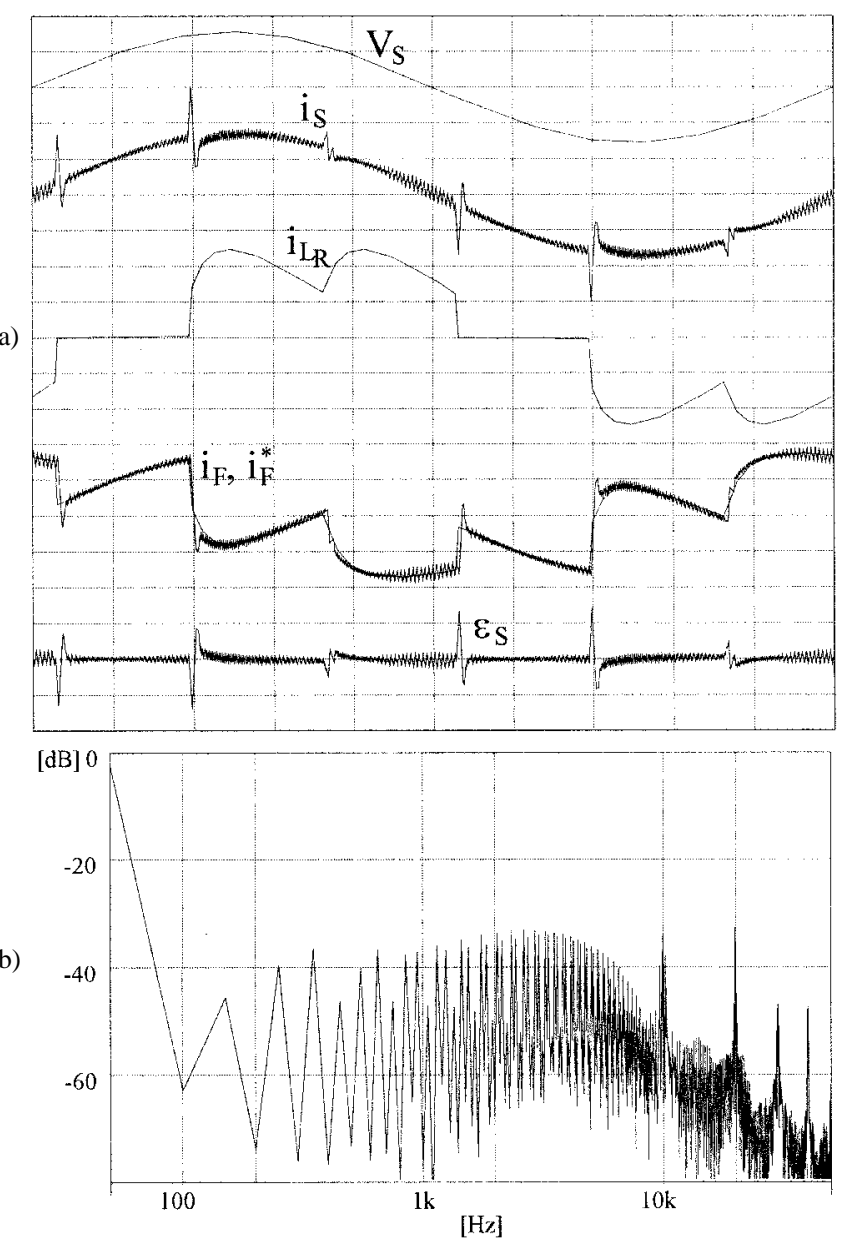

Fig. 7. (a) Simulated active filter behavior with $\alpha=40^{\circ}$ and deadbeat control; $i_{S}(150 \mathrm{~A} / \mathrm{div}), \epsilon_{S}(75 \mathrm{~A} / \mathrm{div}), t(2 \mathrm{~ms} / \mathrm{div})$. (b) Line current $i_{S}$ spectrum.

and are shown in Fig. 9. Again, the spectra current references are the same for both cases. As the load power is unchanged, these references practically coincide with those of the deadbeat control. As can be seen, the linear regulator also exhibits a certain performance degradation as $\alpha$ increases. For this controller, as stated before, the main limitation is represented by the quite low achievable bandwidth of the linear regulator. In this case, the bandwidth is about $2.5 \mathrm{kHz}$. It is worth noting that, since the modulation frequency of the power converter is $10 \mathrm{kHz}$, this value is pretty close to the limit beyond which stability problems may arise. Accordingly, the position of the PI zero is about $1460 \mathrm{~Hz}$, where the open-loop gain is about 1.7 , so as to guarantee a proper phase margin $\left(60^{\circ}\right)$.

Finally, Figs. 10 and 11 describe the behavior of the hysteresis controller for $\alpha=0^{\circ}$ and $\alpha=40^{\circ}$, respectively. All of the details concerning the controller's design can be found in [31]. As can be seen, for this control technique, the quality of the harmonic and reactive power compensation is not significantly affected by the change in the firing angle. Moreover, the effectiveness of frequency regulation can also be appreciated, noting the good definition of the harmonic content near the modulation frequency. the linear current controller for $\alpha=0^{\circ}$. As in the previous case, the same waveforms are evaluated also for $\alpha=40^{\circ}$ technique, occurring at the steep current edges. Thus, the resulting error is much lower than that attained without any compensation.

Fig. 8 reports the results of the system's simulation with 
(a)

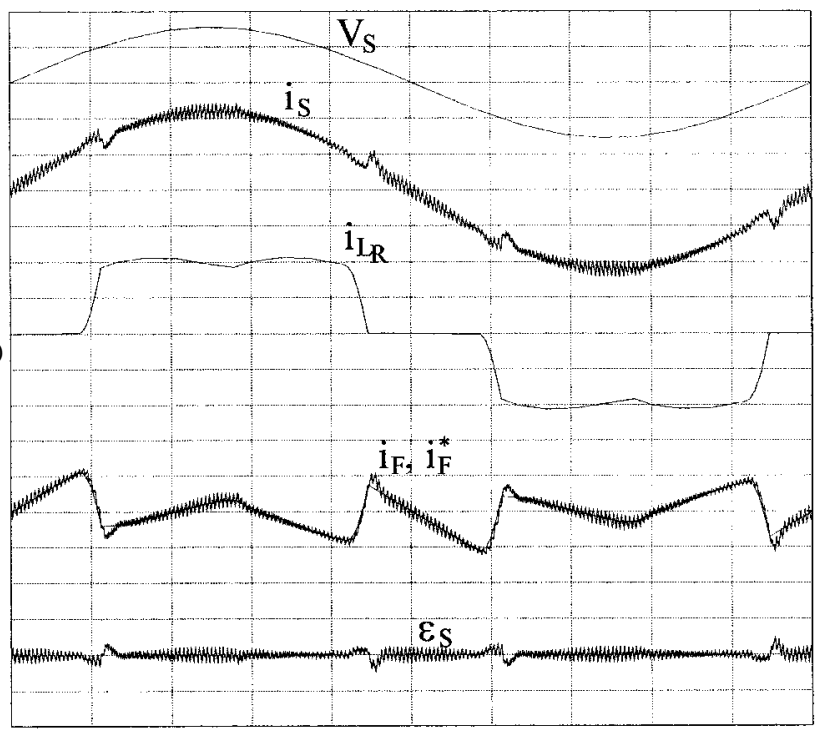

(b)

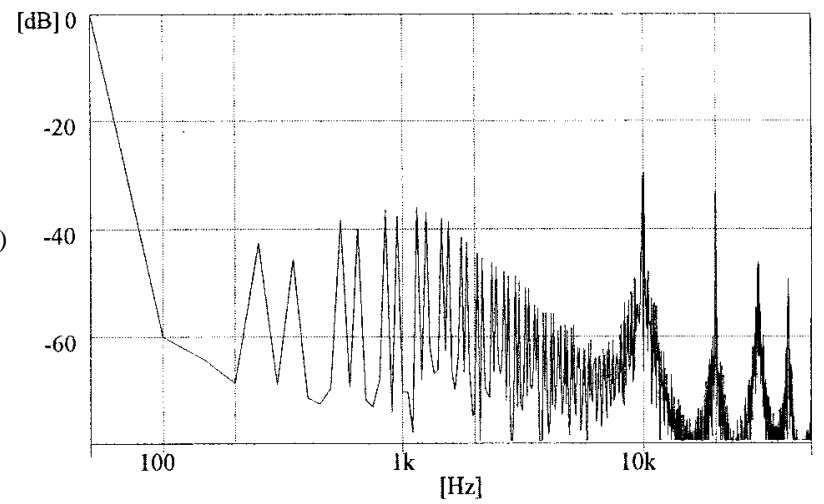

Fig. 8. (a) Simulated active filter behavior with $\alpha=0^{\circ}$ and linear control $i_{S}(150 \mathrm{~A} / \mathrm{div}), \epsilon_{S}(75 \mathrm{~A} / \mathrm{div}), t(2 \mathrm{~ms} / \mathrm{div})(\mathrm{b})$ Line current $i_{S}$ spectrum.

\section{COMPARISON OF Simulation RESUlts}

As stated before, the comparison of the simulation results can be performed by evaluating three indices: the line current spectra, the current error rms value, and the line current THD. Both the rms value and the THD have been calculated in the range of the harmonic components up to a frequency of $2 \mathrm{kHz}$, as required by IEC standards. This choice is also justified by the fact that the high-frequency harmonic components due to the modulation process are always practically eliminated by means of suitable passive filters.

The current spectra were included in the previous section within the figures reporting the simulation results; the normalized rms value of current error and the THD of the line current, both related to the amplitude of the fundamental component of the input current, are given in Tables II and III, respectively. Table II refers to the first considered rectifier firing angle, namely, $\alpha=0^{\circ}$, while Table III refers to $\alpha=40^{\circ}$.

From all indices, it can be seen that a significant superiority of the hysteresis current control technique emerges. The spectra referring to this control technique are, indeed, almost unchanged by the variation of $\alpha$. Moreover, they are at least $20 \mathrm{~dB}$ lower than the spectra referring to the other two control techniques in the range $50 \mathrm{~Hz}-2 \mathrm{kHz}$.
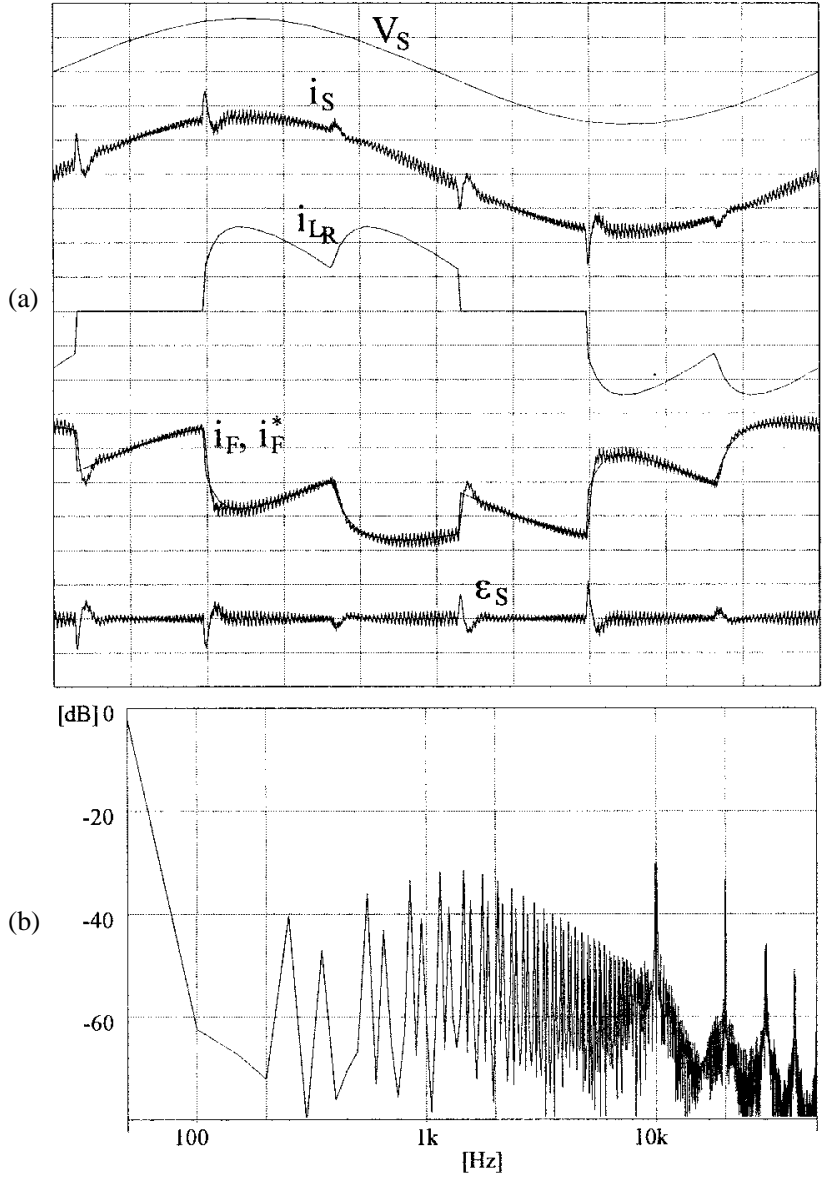

Fig. 9. (a) Simulated active filter behavior with $\alpha=40^{\circ}$ and linear control; $i_{S}(150 \mathrm{~A} / \mathrm{div}), \epsilon_{S}(75 \mathrm{~A} / \mathrm{div}), t(2 \mathrm{~ms} / \mathrm{div})(\mathrm{b})$ Line current $i_{S}$ spectrum.

Thus, as far as IEC standards are concerned, the performance of the linear and deadbeat controllers may not be in any case adequate to meet the standards' requirements, while the hysteresis control, by keeping the harmonics about $60 \mathrm{~dB}$ below the fundamental level, seems not to have particular difficulties in meeting the standards. This superiority is also confirmed by the data reported in Tables II and III, where both the current total harmonic distortion and the error rms value are much lower than those of the linear and deadbeat controls.

It is also possible to notice that the performance of the linear and of the deadbeat controllers turn out to be quite similar. The deadbeat controller exhibits a slight superiority in the case of $\alpha=40^{\circ}$. The linear control's performance, instead, turns out to be slightly more satisfactory in the case of $\alpha=0^{\circ}$, where the bandwidth limitation is not very evident due to the low $d i / d t$ of the current reference. In all cases, it is possible to see that the fundamental component in the current error, which accounts for the difference in the rms and THD figures, is rather small.

\section{CONCLUSIONS}

This paper has discussed the difference in the dynamic performance of the three most popular current control tech- 
(a)
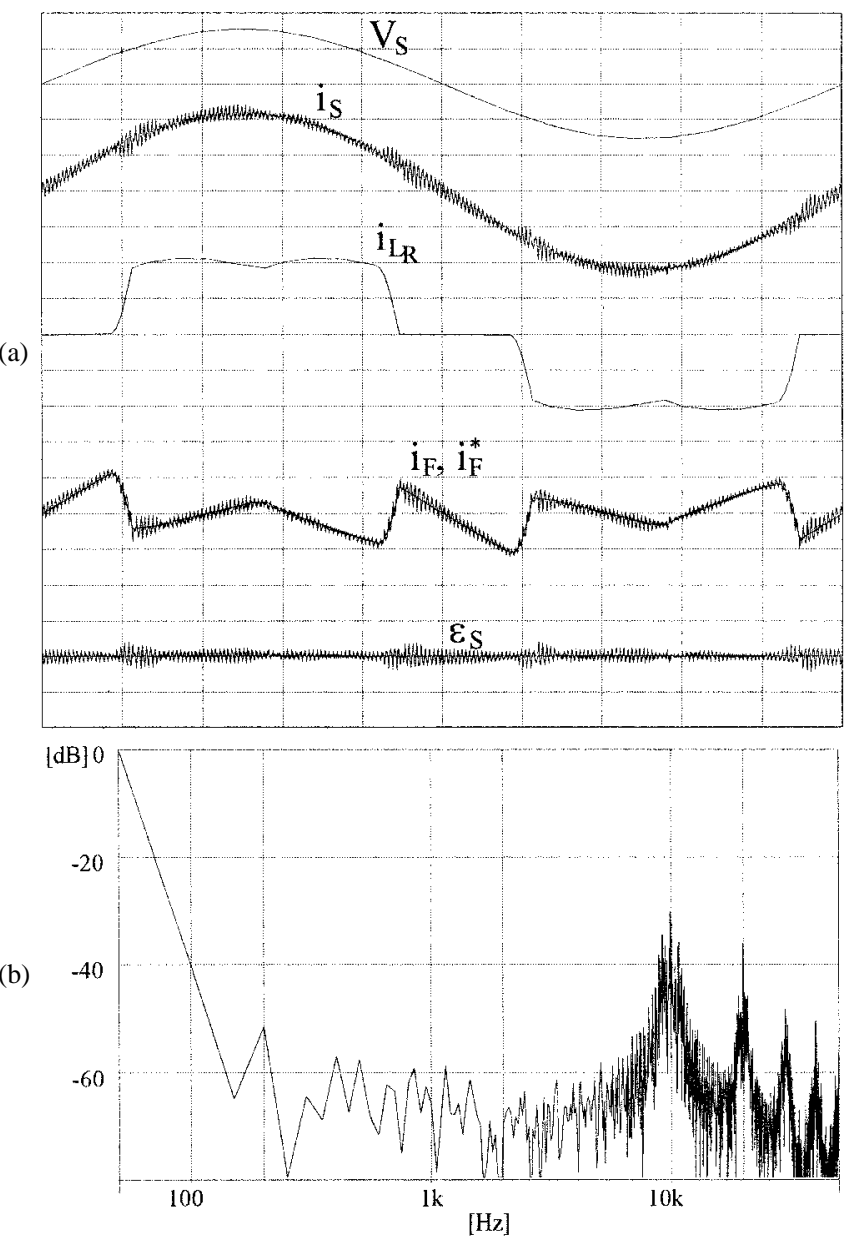

Fig. 10. (a) Simulated active filter behavior with $\alpha=0^{\circ}$ and hysteresis control; $i_{S}(150 \mathrm{~A} / \mathrm{div}), \epsilon_{s}(75 \mathrm{~A} / \mathrm{div}), t(2 \mathrm{~ms} / \mathrm{div})$ (b) Line current $i_{S}$ spectrum.

niques for active filter applications. All the techniques, hysteresis control, deadbeat control, and linear rotating frame control were considered, including the latest improvements brought by their industrial application. The comparison is performed by simulating a typical, high-demanding active filter application where the distorting load to be compensated is a thyristor rectifier. Two different values of the firing angle $\alpha$ were considered to underline the dependence of the achievable performance on the slope of the current reference.

The improvements in the control techniques result in rather satisfactory performance levels for all three controllers. However, the results of the comparison show a certain superiority of the hysteresis control. Indeed, the performance of this control strategy is almost unaffected by the variation in the firing angle and, on the basis of the performance indices considered in the paper, i.e., harmonic content, THD, and rms of the current error, turns out to be better than the other techniques. The deadbeat controller, which has the advantage of being suitable for a fully digital implementation, is limited in its performance by the inherent calculation delay. Instead, the linear control's bandwidth limitation turns into a not completely satisfactory quality of compensation, (a)
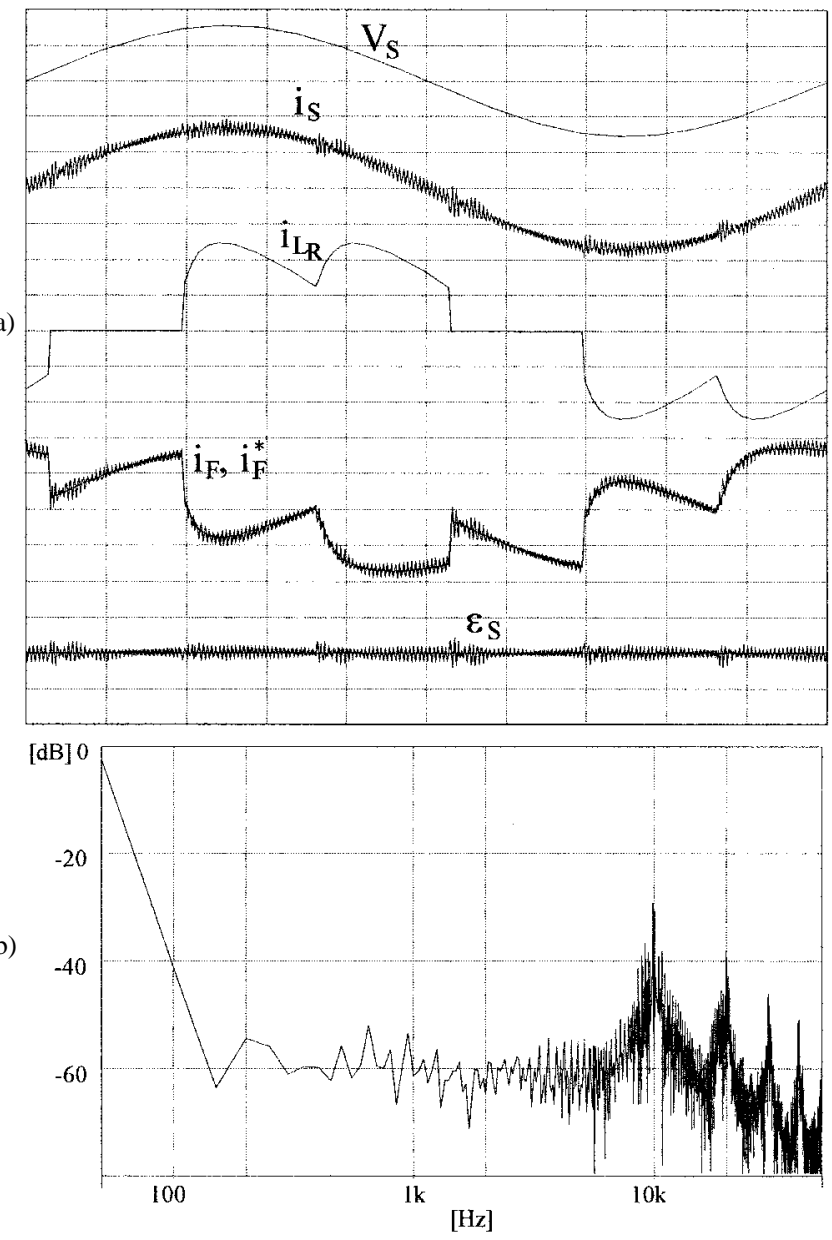

Fig. 11. (a) Simulated active filter behavior with $\alpha=40^{\circ}$ and hysteresis control; $i_{S}(150 \mathrm{~A} / \mathrm{div}), \epsilon_{s}(75 \mathrm{~A} / \mathrm{div}), t(2 \mathrm{~ms} / \mathrm{div})(\mathrm{b})$ Line current $i_{S}$ spectrum.

TABLE II

RMS CURRENT ERROR AND LiNE CURRENT THD FOR $\alpha=0^{\circ}$

\begin{tabular}{cccc}
\hline & Linear Control & Dead Beat Control & Hysteresis Control \\
\hline RMS [\%] & 4.04 & 5.05 & 1.12 \\
THD [\%] & 4.01 & 4.74 & 1.08 \\
\hline
\end{tabular}

TABLE III

RMS CURRENT ERROR AND LiNE CURRENT THD FOR $\alpha=40^{\circ}$

\begin{tabular}{cccc}
\hline & Linear Control & Dead Beat Control & Hysteresis Control \\
\hline RMS [\%] & 7.68 & 7.04 & 1.63 \\
THD [\%] & 7.64 & 6.98 & 1.45 \\
\hline
\end{tabular}

especially in correspondence of high $d i / d t$ in the current reference. 


\section{REFERENCES}

[1] V. R. Stefanovic and R. M. Nelms, "Microprocessor control of motor drives and power converters," in Tutorial Course Rec., IEEE-IAS Annu. Meeting, Dearborn, MI, Oct. 1991, pp. 5/1-35.

[2] D. Wuest and F. Jenni, "Space vector based current control schemes for voltage source inverters," in Conf. Rec. IEEE PESC'93, Seattle, WA, 1993, pp. 986-992.

[3] H. W. Van der Broeck, H. C. Skudelny, and G. V. Stanke, "Analysis and realization of a pulse width modulator based on voltage space vectors," IEEE Trans. Ind. Applicat., vol. 24, pp. 142-150, Jan./Feb. 1988.

[4] D. M. Brod and D. W. Novotny, "Current control of VSI-PWM inverters," IEEE Trans. Ind. Applicat., vol. IA-21, pp. 562-570, July/Aug. 1985.

[5] J. W. Dixon, S. Tepper, and L. Moran, "Analysis and evaluation of different modulation techniques for active power filters," in Proc. IEEE APEC'94, 1994, pp. 894-900

[6] M. P. Kazmierkowski and M. A. Dzieniakowski, "Review of current regulation techniques for three-phase PWM inverters," in Proc. IEEE IECON'94, 1994, pp. 567-575

[7] H. Akagi and A. Nabae, "Control strategy of active power filters using multiple voltage source PWM converters," IEEE Trans. Ind. Applicat., vol. IA-22, pp. 460-465, May/June 1986.

[8] L. Malesani, L. Rossetto, and P. Tenti, "Active filter for reactive power and harmonics compensation,"in Proc. IEEE PESC'86, 1986, pp. 321-330.

[9] T. M. Rowan and R. J. Kerkman, "A new synchronous current regulator and an analysis of current regulated PWM inverters," IEEE Trans. Ind. Applicat., vol. IA-22, pp. 678-690, July/Aug. 1986.

[10] T. M. Rowan, R. J. Kerkman, and T. A. Lipo, "Operation of naturally sampled current regulators in the transition region," IEEE Trans. Ind. Applicat., vol. IA-23, pp. 586-596, July/Aug. 1987.

[11] C. T. Rim, N. S. Choi, G. C. Cho, and G. H. Cho, "A complete DC and AC analysis of three-phase controlled-current PWM rectifier using circuit D-Q transformation," IEEE Trans. Power Electron., vol. 9, pp. 390-396, July 1994.

[12] N. R. Zargari and G. Joos, "Performance investigation of a currentcontrolled voltage-regulated PWM rectifier in rotating and stationary frames," in Proc. IEEE IECON'93, 1993, pp. 1193-1198.

[13] D. G. Holmes and D. A. Martin, "Implementation of direct digital predictive current controller for single and three phase voltage source inverters," in Conf. Rec. IEEE-IAS Annu. Meeting, 1996, pp. 906-913.

[14] H. Le-Huy, K. Slimani, and P. Viarouge, "A predictive current controller for synchronous servo drives," in Proc. European Conf. Power Electronics and Applications, Florence, Italy, Sept. 1991, pp. 2.114-2.119.

[15] T. G. Habetler, "A space vector based rectifier regulator for AC/DC/AC converters," in Proc. European Conf. Power Electronics and Applications, Florence, Italy, Sept. 1991, pp. 2.101-2.107.

[16] A. Kawamura, T. Haneyoshi, and R. G. Hoft, "Deadbeat controlled PWM inverter with parameter estimation using only voltage sensor," in Proc. IEEE PESC'86, 1986, pp. 576-583.

[17] T. Kalker, A. Ackva, and U. Jansen, "Novel digital controller for induction machines considering the inverter switching times and a fluctuating dc-link voltage," in Proc. European Conf. Power Electronics and Applications, Florence, Italy, Sept. 1991, pp. 2.058-2.063.

[18] H. Le-Huy, "Microprocessors and digital IC's for motion control," Proc. IEEE, vol. 82, pp. 1140-1163, Aug. 1994.

[19] K. P. Gokhale, A. Kawamura, and R. G. Hoft, "Dead beat microprocessor control of PWM inverter for sinusoidal output waveform synthesis," IEEE Trans. Ind. Applicat., vol. IA-23, pp. 901-909, Sept./Oct. 1987.

[20] T. Kawabata, T. Miyashita, and Y. Yamamoto, "Dead beat control of three phase PWM inverter," IEEE Trans. Power Electron., vol. 5, pp. 21-28, Jan. 1990

[21] T. Ohnuki, O. Miyashita, T. Haneyoshi, and E. Ohtsuji, "High power factor PWM rectifiers with an analog pulsewidth prediction controller," IEEE Trans. Power Electron., vol. 11, pp. 460-465, May 1996.

[22] P. Tenti, A. Zuccato, L. Rossetto, and M. Bortolotto, "Optimum digital control of PWM rectifiers," in Proc. IEEE IECON'94, 1994, pp. 382-387.
[23] S. Buso, L. Malesani, P. Mattavelli, and R. Veronese, "Design and fully digital control of parallel active filters for thyristor rectifiers," in Conf. Rec. IEEE-IAS Annu. Meeting, 1997, pp. 1360-1367.

[24] Z. Radulovic and A. Sabanovic, "Active filter control using a sliding mode approach," in Proc. IEEE PESC'94, 1994, pp. 177-182.

[25] A. Kawamura and R. G. Hoft, "Instantaneous feedback controlled PWM inverters with adaptive hysteresis," IEEE Trans. Ind. Applicat., vol. IA-20, pp. 769-775, July/Aug. 1984.

[26] C. Chiarelli, L. Malesani, S. Pirondini, and P. Tomasin, "Singlephase, three-level, constant frequency current hysteresis control for UPS applications," in Proc. European Conf. Power Electronics and Applications, Brighton, U.K., Sept. 1993, pp. 180-185.

[27] L. Malesani and P. Tenti, "A novel hysteresis control method for current controlled VSI PWM inverters with constant modulation frequency," IEEE Trans. Ind. Applicat., vol. 26, pp. 88-92, Jan./Feb. 1990.

[28] Q. Yao and D. G. Holmes, "A simple, novel method for variablehysteresis-band current control of a three phase inverter with constant switching frequency," in Conf. Rec. IEEE-IAS Annu. Meeting, Toronto, Ont., Canada, Oct. 1993, pp. 1122-1129.

[29] L. Malesani, P. Mattavelli, and P. Tomasin, "Improved constant frequency hysteresis current control of VSI inverters with simple feedforward bandwidth prediction," in Conf. Rec. IEEE-IAS Annu. Meeting, Lake Buena Vista, FL, Oct. 1995, pp. 2633-2640.

[30] L. Sonaglioni, "Predictive digital hysteresis current control," in Conf Rec. IEEE-IAS Апnи. Meeting, Lake Buena Vista, FL, Oct. 1995, pp. $1879-1886$.

[31] L. Malesani, P. Mattavelli, P. Tomasin, "High-performance hysteresis modulation technique for active filters," in Proc. IEEE APEC'96, 1996, pp. 939-946.

[32] S. Bhattacharya, T. M. Frank, D. M. Divan, and B. Banerjee, "Parallel active filter system implementation and design issues for utility interface of adjustable speed drive systems," in Conf. Rec. IEEE-IAS Annu. Meeting, 1996, pp. 1032-1039.

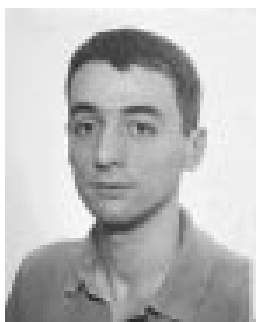

Simone Buso (M'98) received the Dr. degree (with honors) and the Ph.D. degree, both in electronic engineering, from the University of Padova, Padova, Italy, in 1992 and 1996, respectively.

Since 1998, he has been a Researcher in the Department of Electronics and Informatics, University of Padova. His major fields of interest include analysis and control of power converters, digital control techniques, and computer simulation of power electronic circuits.

Luigi Malesani (M'63-SM'93-F'94), for a photograph and biography, see this issue, p. 690.

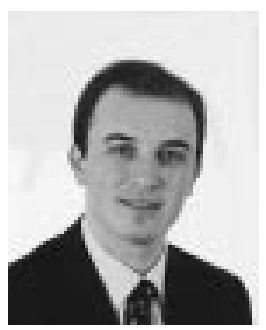

Paolo Mattavelli (S'95-A'96) received the Dr. degree (with honors) and the Ph.D. degree, both in electrical engineering, from the University of Padova, Padova, Italy, in 1992 and 1995, respectively.

He has been a Researcher with the Department of Electrical Engineering, University of Padova, since 1995. His major fields of interest include static power conversion, control techniques, and digital simulation.

Dr. Mattavelli is a member of the IEEE Power Electronics, IEEE Industry Applications, and IEEE Power Engineering Societies and the Italian Association of Electrical and Electronic Engineers. 